\title{
Case report. Invaginatie van de ureter door een ureter-fibro-epitheliale poliep
}

\author{
Yael C. Flippo $^{1}$ Rob P. W. F. Wijn ${ }^{1}$ Elmer A. E. Francisca ${ }^{1}$
}

Published online: 28 July 2016

(C) The Author(s) 2016. This article is available at SpringerLink with Open Access.

Samenvatting De ureter-fibro-epitheliale poliep (UFP) is een zeldzame benigne tumor. Een invaginatie veroorzaakt door een UFP is nog veel zeldzamer. Aanbevelingen voor diagnostiek en behandelingen zijn veelal op basis van eerdere case reports en meningen van experts. Veelal is de UFP asymptomatisch en is het enige symptoom microscopische hematurie. Diagnostisch zijn de CT-scan met een intraveneuze pyelografie en de diagnostische ureterorenoscopie (URS) middel van eerste keus. Behandeling bestaat uit endoscopische, laparoscopische of open chirurgische resectie, afhankelijk van locatie en grootte van de tumor. Wij presenteren een casus met een UFP die een ureterinvaginatie veroorzaakt.

Trefwoorden ureter-fibro-epitheliale poliep (UFP) · ureterinvaginatie $\cdot$ tumor

\section{Case report. Ureteral invagination caused by ureteral fibroepithelial polyp}

\begin{abstract}
The ureteral-fibro-epithelial polyp (UFP) is a rare benign tumor. An invagination of the ureter caused by a UFP is even rarer. Recommendations regarding diagnostics and treatment are based on previous case reports and expert opinions. UFP is mostly asymptomatic with microscopic hematuria as first symptom. CT with intravenous pyelography and a diagnostic ureterorenoscopy (URS) are best diagnostics options. Treatment is based on radical
\end{abstract}

drs. Rob P. W. F. Wijn

rob.wijn@mumc.nl

1 Maastricht Universitair Medisch Centrum+, Maastricht, Nederland resection by endoscopic, laparoscopic or open procedure, depending on location and size. We present a case with a UFP causing a ureteral invagination.

Keywords ureteral-fibro-epithelial-polyp · ureteral invagination $\cdot$ tumor

\section{Introductie}

Een ureter-fibro-epitheliale poliep (UFP) is een zeldzame benigne tumor, die afkomstig is van het mesoderm van de ureter en is bedekt met normaal urotheel. Ongeveer $20 \%$ van alle uretertumoren is benigne van aard [1]. Ongeveer $28 \%$ daarvan zijn fibro-epitheliale poliepen [2].

De etiologie van de UFP is niet bekend, maar in de literatuur zijn postinfectieuze, congenitale, obstructieve en traumatische oorzaken beschreven [3]. UFP's komen meestal unilateraal voor als solitaire laesie. De meeste UFP's zijn kleiner dan $6 \mathrm{~cm}$, maar sommige kunnen ook langer zijn dan $15 \mathrm{~cm}$. UFP's kunnen asymptomatisch voorkomen of klachten geven van flankpijn of macroscopische hematurie [2-4]. Dat een zeldzame UFP een ureterinvaginatie veroorzaakt, is zelden beschreven [2].

\section{Casus}

Een 53-jarige vrouw presenteerde zich met macroscopische hematurie en suprapubische pijnklachten. Er waren geen tekenen van een urineweginfectie. Ze was drie jaar geleden gestopt met roken. Patiënte had in de voorgeschiedenis een cervixcarcinoom FIGO IIb waarvoor zij chemoradiatie kreeg. Bij lichamelijk onderzoek werden geen afwijkingen gevonden. Het creatininegehalte bedroeg 67 umol/l en 


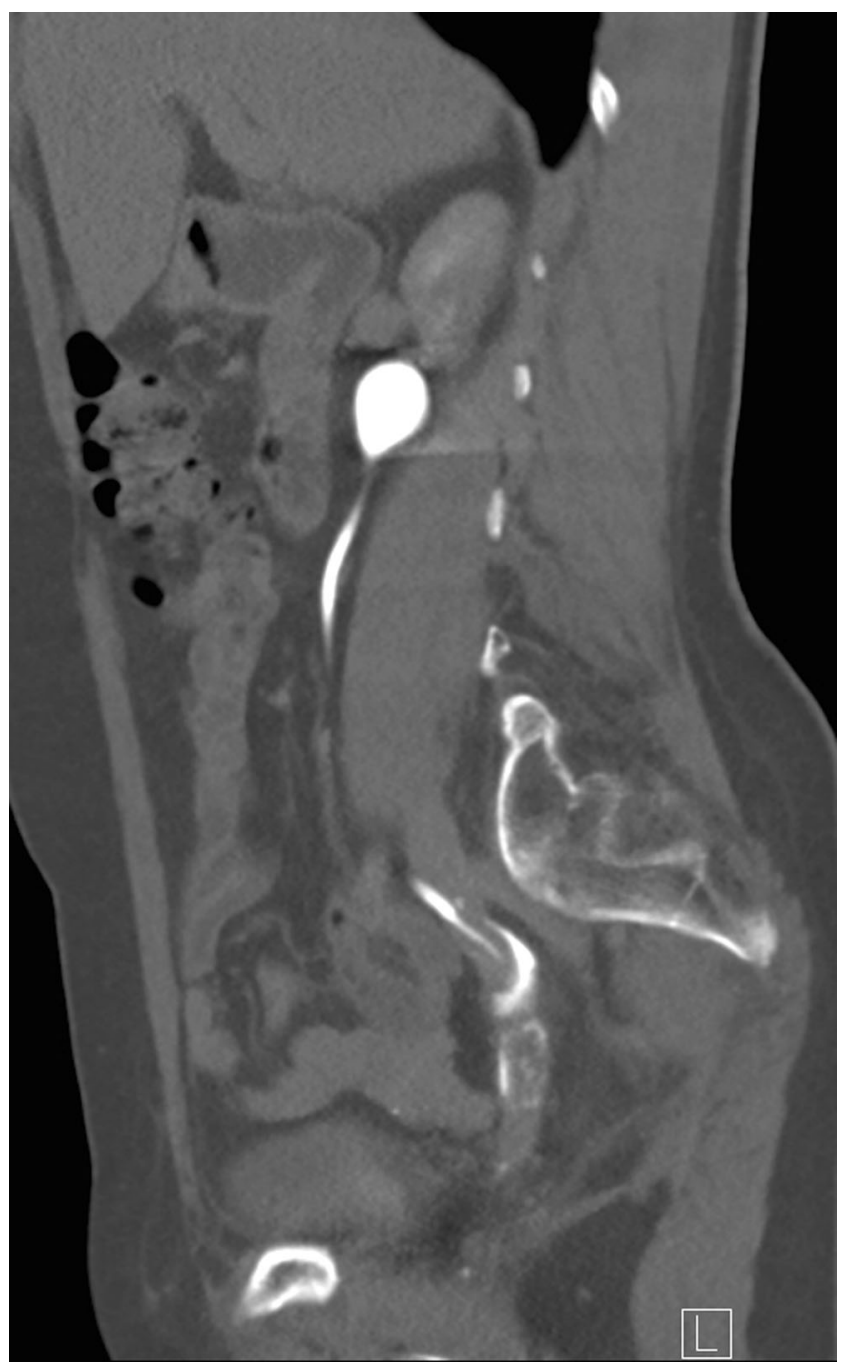

Figuur 1 CT-IVP. Vullingsdefect van distale ureter rechts

het gehalte aan carcino-embryonaal antigeen (CEA) was $0,9 \mathrm{ug} / \mathrm{l}$. In het urinesediment werden erytrocyten aangetroffen en de urinecytologie vertoonde atypische urotheelcellen. Bij cystoscopie werd het beeld gezien van radiatiecystitis en op een aanvullende CT-IVP-scan werd een afwijking gezien in de distale ureter rechts die verdacht was voor een distale uretertumor over een traject van $9 \mathrm{~cm}$ (fig. 1). Er waren geen aanwijzingen voor lymfadenopathie.

Er vond een diagnostische ureterorenoscopie (URS) plaats. In de distale ureter zat een gladde gesteelde tumor, waarvan een biopt werd genomen. Met de semirigide ureterorenoscoop (Stortz Ch 9,5) konden we de tumor niet passeren, waardoor de basis niet kon worden geïdentificeerd. Ook kon er geen voerdraad worden opgevoerd richting de nier. Endoscopische resectie was hierdoor niet mogelijk. Er werd alleen een biopt genomen.

De pathologie van het tumorbiopt toonde stromaal gelegen atypisch urotheel. Aanvullend werd een renogram gemaakt, waarop we een partiële obstructie zagen van de rechternier, met een functieverdeling van $41 \%$ rechternier en $59 \%$ linkernier.

Omdat patiënte pijnklachten en macroscopische hematurie bleef houden, werd besloten om een tumorresectie middels ureterotomie te verrichten. Dit gebeurde middels een extraperitoneale open procedure vanwege eerdere radiatie. Het gedilateerde traject en het niet-gedilateerde uretertraject konden worden geïdentificeerd en vrijgelegd. Via een ureterotomie werd de ureter onder de tumor geopend; hierbij zagen we een benigne ogende massa met normaal urotheel met een lumen waarin peristaltiek te zien was (fig. 2). De tumormassa bleek een invaginatie van de ureter over $1 \mathrm{~cm}$ te hebben veroorzaakt, met proximaal en distaal hiervan een normale ureter.

Proximaal van de tumor werd de ureter geïncideerd. Een voerdraad werd vanaf proximaal opgevoerd en kwam distaal in een lumen terecht, wat wijst op invaginatie. De polypeuze massa werd en bloc verwijderd. Met een flexibele ureterorenoscoop werd ook de distale ureter nog gecontroleerd. Daar werd geen resttumor gezien. Beide ureteruiteinden werden gespatuleerd en er werd een primaire anastomose aangelegd over een $\mathrm{JJ}$ ch8. Rondom de ureteranastomose werd een omental wrap aangebracht.

De totale operatietijd bedroeg 188 minuten met een totaal bloedverlies van $50 \mathrm{cc}$. Postoperatief verliep het herstel spoedig. De preoperatieve pijn was daags na de operatie verdwenen. De JJ werd zes weken na de operatie zonder problemen verwijderd. Pathologisch-anatomisch onderzoek toonde een fibro-epitheliale poliep aan, zonder aanwijzingen voor maligniteit (fig. 3).

Patiënte is een halfjaar na diagnose en excisie nog steeds klachtenvrij. Een aanvullende CT-IVP-scan liet geen recidief UFP zien.

\section{Discussie}

Een UFP is een zeldzame benigne tumor, die voor het eerst is beschreven in 1932 [3]. Andere benigne tumoren van de ureter zijn endometrioma, fibroma, leiomyoma, neurofibroma, lymfangioma en hemangioma. De etiologie van de fibro-epitheliale poliep is nog onduidelijk. Een hypothese is dat deze poliepen langzaam groeiende congenitale afwijkingen zijn. Een andere hypothese is dat deze poliepen het gevolg zijn van chronische urotheliale irritatie, zoals lithiasis, infecties of dubbel-J-stents. De prevalentie onder jongvolwassen vrouwen met recidiverende UWI's is echter niet verhoogd, wat infecties als causale factor minder waarschijnlijk maakt [3]. Bolton et al. vonden in hun review met 116 case reports slechts bij zes casus een bewezen bacteriologisch UWI voorafgaande aan de diagnose [5]. 

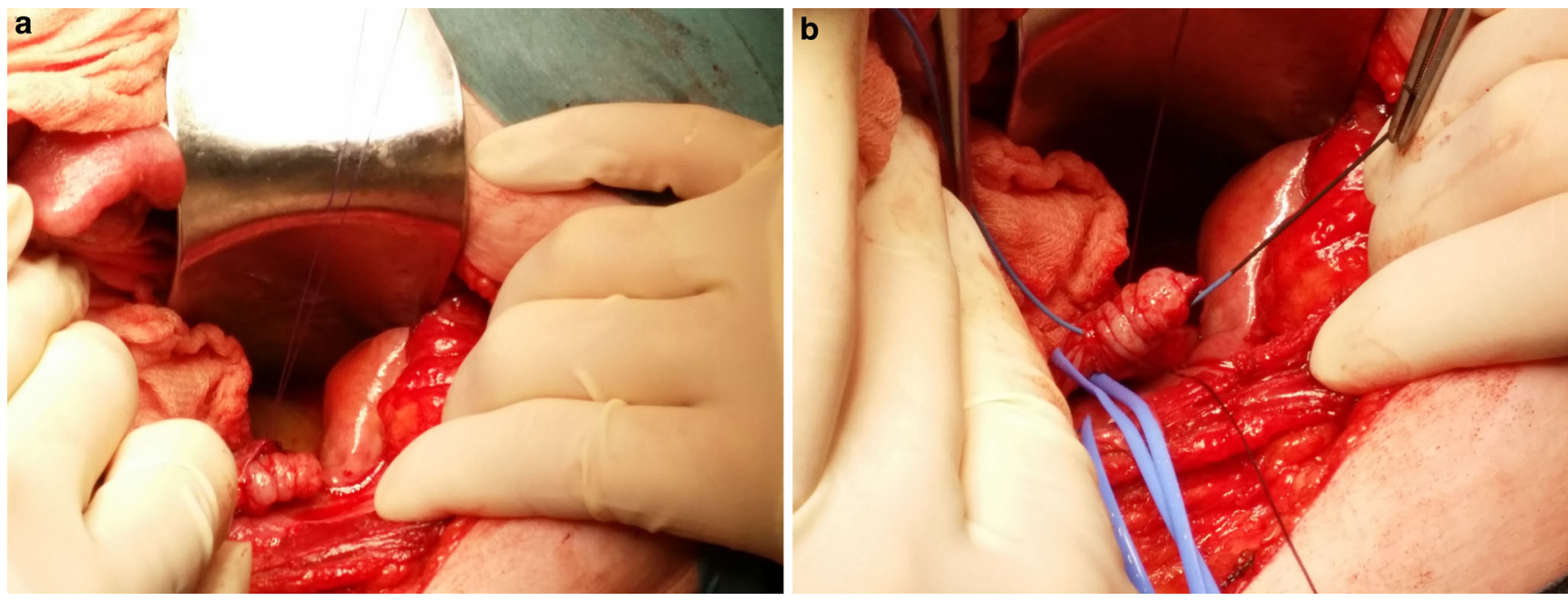

Figuur 2 a Ureterinvaginatie na de ureterotomie. b Het lumen van proximaal gezien, dat met een voerdraad is gekanaliseerd

UFP's komen voor op kinderleeftijd, maar treden toch voornamelijk op bij 30-40-jarigen. In de meeste literatuur is terug te vinden dat de man-vrouwratio op ongeveer 3:2 ligt en dat de linkerureter vaker is aangedaan dan de rechter en dan met name bij kinderen [5]. Deze bevinding wordt echter niet ondersteund door de systematische review van Ludwig et al. met studies onder volwassenen [6]. 55,9\% van de 131 volwassen patiënten bleek vrouw te zijn en de poliepen waren gelijkelijk verdeeld over beide ureters. De mediane grootte was $4 \mathrm{~cm}$ met een range van $0,4-17 \mathrm{~cm}$. Bij $41,7 \%$ van de patiënten zorgde de poliep voor hydronefrose.

De poliepen kunnen overal in de urinewegen voorkomen. $\mathrm{Bij}$ volwassenen wordt het merendeel in het proximale deel van de ureter gevonden. Pediatrische UFP's zijn vaak gelokaliseerd ter hoogte van de ureteropelviene junctie (UPJ) en het bovenste deel van de ureter. Meestal presenteert de uretherale poliep zich als een solitaire tumor, maar er zijn ook case reports over multipele en bilaterale poliepen beschreven $[3,7]$.

De meest voorkomende klachten waar patiënten zich mee presenteren zijn micro- of macroscopische hematurie. Patiënten kunnen echter compleet asymptomatisch zijn of zich presenteren met niet-gerelateerde symptomen. Bij sommige patiënten zit daarom een lang interval tussen de klachten en de diagnose. Kolieken doen zich gewoonlijk alleen voor bij grote poliepen en als de tumor op de overgang van pyelum naar ureter is gelokaliseerd. Dikwijls wordt geringe flankpijn gemeld. Indien de poliep in het meest distale deel van de ureter zit, kan de patiënt klachten als frequency en strangurie krijgen.

Het feit dat een UFP symptomatisch en radiologisch een maligne tumor nabootst, zorgt voor een diagnostisch dilemma. De herhaaldelijke negatieve uitslag bij urinecytologie zou een aanwijzing kunnen zijn voor een benigne tumor.
Een CT-scan (met een contrastfase) kan de anatomie en de lokalisatie van de afwijking helpen verduidelijken, waarbij onderscheid gemaakt zou kunnen worden tussen een poliep die uitgaat van de ureterwand of een maligniteit. Op radiologische beelden wordt, net als in onze casus, vaak een vullingsdefect gezien in het verloop van de ureter [8]. Uiteindelijk is ureteroscopie met biopten nodig om te kunnen differentiëren tussen een maligne of een benigne massa. Ureterpoliepen zijn gesteelde langwerpige vormsels en hebben een glad grijsroze gekleurd oppervlak. Ze hebben een vaste consistentie.

Histologisch gezien worden fibro-epitheliale poliepen geclassificeerd als benigne hamartoma. Ze worden gekarakteriseerd door losmazig vasculair fibreus stroma, dat vanuit het submucosa opkomt, met daaroverheen een laag urotheel. Grote UFP's kunnen, in zeer zeldzame gevallen, zoals onze casus illustreert, ureterinvaginatie veroorzaken.

De behandeling van UFP is complete resectie. Dit kan via een endoscopische, laparoscopische of open benadering. Endoscopische resectie dient als de gouden standaard beschouwd te worden. De meeste poliepen werden weggehaald middels ureter-endoscopische resectie of een Holmium YAG-laser. Endoscopische resectie is lastig bij grote of proximaal gelegen poliepen [6,9]. Echter, succesvolle endoscopische resecties van $16 \mathrm{~cm}$ lange poliepen zijn gerapporteerd [10].

Een voldoende grote marge is aan te raden om incomplete verwijdering, en daarmee een recidief, te voorkomen. Geadviseerd wordt na drie maanden een CT-IVP-scan en na één jaar een echo van de urinewegen te maken, om late complicaties op te sporen [6]. 


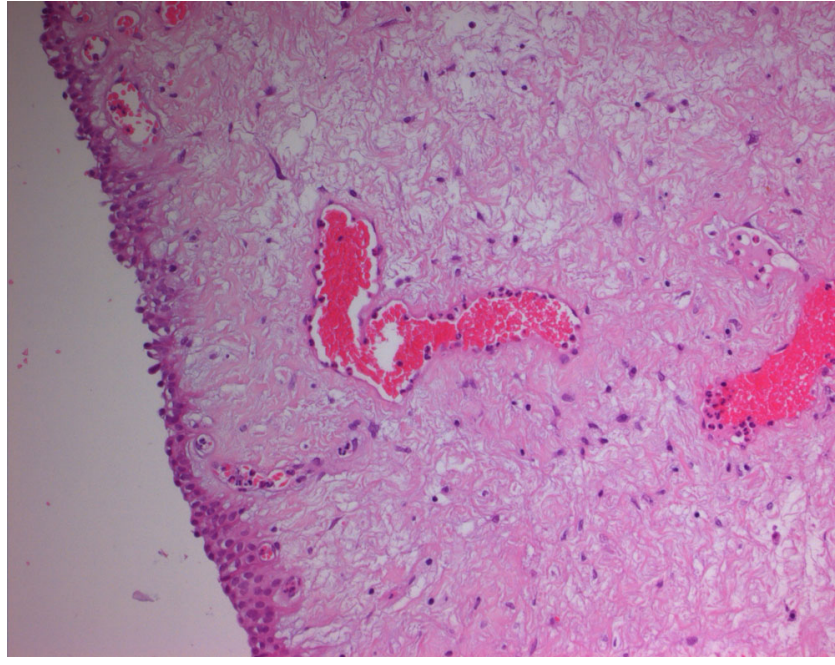

Figuur 3 Microscopisch beeld van de fibro-epitheliale poliep met bekledend urotheel en gestuwde vaten

\section{Conclusie}

Wanneer men bij hematurie herhaaldelijk negatieve urinecytologie vindt, in combinatie met een vullingsdefect in het verloop van de (meestal proximale) ureter op een CTIVP-scan, moet men bedacht zijn op een zeldzame benigne tumor, namelijk een ureter fibro-epitheliale-poliep (UFP). Onze casus illustreert dat een UFP naast hematurie, flankpijn en hydronefrose in zeer zeldzame gevallen ook ureterinvaginatie kan veroorzaken. Ter differentiatie tussen een poliep en een maligniteit zijn biopten middels een URS of pathologisch onderzoek van de tumor van belang. De gouden standaard voor de behandeling van UFP's is endoscopische resectie. Is endoscopische resectie niet mogelijk, zoals bij grote of proximale poliepen en, in ons geval, bij een ureter-invaginatie, kan gekozen worden voor een laparoscopische of open benadering.
Open Access This article is distributed under the terms of the Creative Commons Attribution 4.0 International License (http:// creativecommons.org/licenses/by/4.0/), which permits unrestricted use, distribution, and reproduction in any medium, provided you give appropriate credit to the original author(s) and the source, provide a link to the Creative Commons license, and indicate if changes were made.

\section{Literatuur}

1. Franca I, Choudhury M, Eshgi M, Bhalodi A, Addonizio JC, et al. Fibroepithelial polyp associated with congenital diverticulum. Report of 2 cases. J Urol. 1998;140:598-600.

2. Hasegawa Y, Mita K, Ueki T, Ishida Y, Koda S, Seno Y, Nakamoto T, Matsubara A. Retroperitoneoscopic treatment of ureteral invagination caused by a long fibroepithelial polyp protruding into the bladder: report of a case. Surg Today. 2011;41(8):1117-21.

3. Tekdogan UY, Canakli F, Aslan Y, Han O, Gungor S, Atan A. Case report. Bilateral ureteral fibroepithelial polyps and review of the literature. Int J Urol. 2005;12:98-100.

4. Melicow M, Findlay HV. Primary benign tumors of ureter: review of literature and report of case. Surg Gynecol Obstet. 1932;54:680-9.

5. Bolton D, Stoller ML, Irby P. Fibroepithelial ureteral polyps and urolithiasis. Urology. 1994;44:582-7.

6. Ludwig DJ, Buddingh KT, Kums JJ, Kropman RF, Roshani H, Hirdes WH. Treatment and outcome of fibroepithelial ureteral polyps: a systematic literature review. Can Urol Assoc J. 2015;9(9-10):E631-E637.

7. Dolan R, Morton S, Granitsiotis P. Presentation of a benign fibroepithelial polyp with frank haematuria: an unusual diagnosis. Scot Med J. 2015;60(1):E24-6.

8. Dunnick NR, Sandler CM, Newhouse JH. et al. Pelvicalyceal system and ureter, textbook of uroradiology, 5th. ed. Londen: Lippincott Williams \& Wilkins; 2001.

9. Kijvikai K, Maynes LJ, Herrell SD. Laparoscopic management of large ureteral fibroepithelial polyp. Urology. 2007;70:373:E4-7.

10. Sun Y, Xu C, Wen X, Ren S, Ye H, Gao X, Gao X. Is endoscopic management suitable for long ureteral fibroepithelial polyps? J Endourol. 2008;22:1459-62.

Yael C. Flippo co-assistant urologie

drs. Rob P.W.F. Wijn aios urologie

dr. Elmer A.E. Francisca uroloog 